\title{
Surface charge characterization of metal oxides by potentiometric acid-base titration, revisited theory and experiment
}

Márta Szekeres* and Etelka Tombácz*

Department of Physical Chemistry and Materials Science, University of Szeged, Aradi vt. 1, 6720 Szeged, Hungary

\section{Corresponding authors}

Address: Department of Physical Chemistry and Materials Science, University of Szeged, Aradi vt. 1, 6720 Szeged, Hungary

Tel: +36-62-544212

E-mail addresses: szekeres@chem.u-szeged.hu (M. Szekeres), tombacz@chem.u-szeged.hu (E. Tombácz)

\section{Graphical abstract}

Four-step potentiometric acid/base titration procedure of exact characterization of $\mathrm{pH}$ dependent surface charging of metal oxides

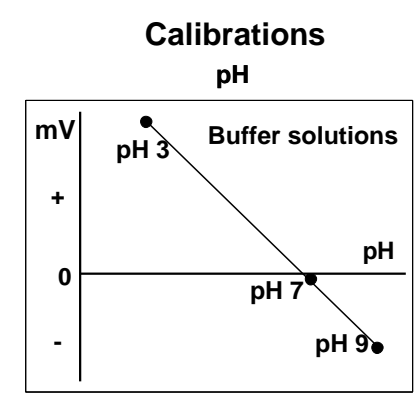

Proton concentration

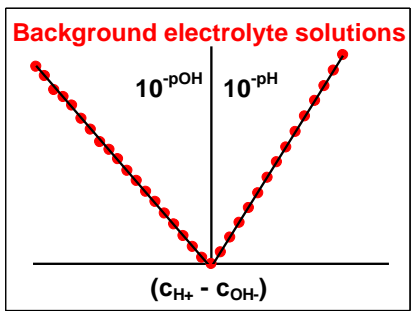

Proton balance Consumption

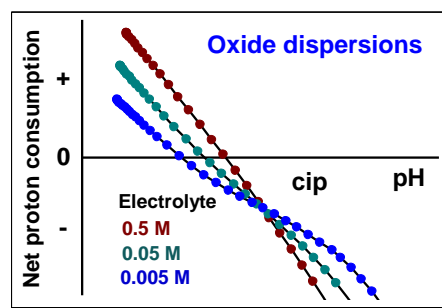

Gibbs surface excess

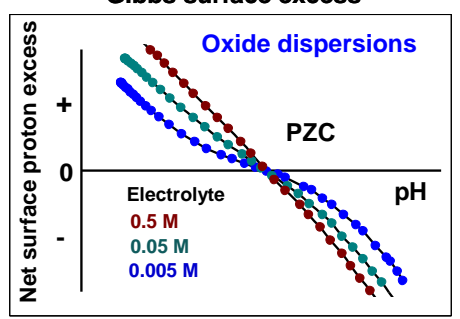

\section{Highlights}

- Straightforward protocol for pHdependent charge determination of oxide nanoparticles.

- Response of glass electrode must be tested in background electrolytes, too.

- Proton concentration calibration is needed to calculate surface proton balance.

- The primary result is merely net proton consumption, not necessarily surface excess.

- Surface charge density can only be obtained, if any interfering effects are excluded.

\section{Abstract}

The increased interest in architecting nanocomposites and in clarifying their impact on health and environment necessitates a standardized method of surface characterization, because the behaviour of nanoparticles is governed largely by their surface free energy and interfacial chemistry. Potentiometric acid-base titration has been used for decades to determine surface charge density of oxides, tremendously useful in understanding and modelling oxide/electrolyte interfaces. The method has solid theoretical and experimental foundation. Yet, published values of the point of zero charge (PZC) of chemically identical oxides scatter 
This is a PDF file of an unedited manuscript that has been accepted for publication. Final edited form is published in Colloids and Surfaces A, 2012, 414:302-313. http://dx.doi.org/10.1016/j.colsurfa.2012.08.027

widely: the deviation of seven units of $\mathrm{pH}$ is the rule, rather than an exception. The PZC must reflect the inherent charging behaviour, linked exclusively to the protonation, and determined by the chemistry of the oxides. Assignment of PZC (just like assignment of equilibrium constant of any chemical reaction) requires strict conditions and consistent protocol. We present here such a protocol, and some examples of application. The protocol leads through the basic steps: $\mathrm{pH}$ buffer calibration, proton concentration calibration in the background electrolytes, and titrations of oxides. Built-in tests help to eliminate artificial side effects simultaneously from the measurement of $\mathrm{pH}$ and from the oxide/electrolyte interfacial equilibria. Although these may seem self-evident, literature survey proves the need to go back to basics in order to obtain precise, reliable and comparable $\mathrm{pH}$-dependent charging of oxides. It is most general that the oxides contain some unrecognized surface impurities and have a strongly $\mathrm{pH}$-dependent dissolution. These distort the results of titrations; their effect increases with decreasing particle size and can become dominant for nanoparticles. The protocol presented here contains the necessary feedback loops to easily recognize and exclude these side effects.

\section{Keywords}

Oxide nanoparticles, Surface charge, $\mathrm{pH}$ measurement, PZC, Dissolution, Specific ions

\section{Introduction}

Recently, oxides (e.g., $\mathrm{TiO}_{2}, \mathrm{Al}_{2} \mathrm{O}_{3}, \mathrm{ZnO}, \mathrm{Fe}$-oxide, $\mathrm{SiO}_{2}$ ) are often prepared in the form of nanoparticles, because their properties are advantageous compared to the macroscopic phase [1]. Nanotechnology exploits this by incorporating nanoparticles in nanocomposites or using them as vehicles for a variety of aims in both technology and material and life sciences. The technological use, environmental circulation [2,3] and toxicity [4-6] of nanoparticles depend on their surface chemistry, charge and state of aggregation. Therefore, the characterization of the intrinsic surface charging behaviour of oxide nanoparticles is of primary importance. The knowledge of the latter with the highest possible certainty is inevitable in architecting tailor-made nanocomposites, because nanosystems are even more sensitive to the experimental conditions, e.g., $\mathrm{pH}$, specifically adsorbing ions, surface complexation reactions and particle attachment to surfaces or macromolecules, than macro systems. In addition, the increasing surface charge density of nanoparticles further increases the rate of dissolution [7], as compared to the Ostwald ripening process describing the behaviour of uncharged particles. Due to the increased surface/mass ratio, the specific amount of surface charge (related to the unit mass of solid) increases gradually with decreasing particle size.

Potentiometric acid-base titration is the most straightforward method of characterizing surface charging equilibria of oxides, since surface charge develops in the process of protonation/deprotonation of surface hydroxyl groups, designated as $\mathrm{SOH}$, which have distinct chemical identity at $\mathrm{pH}$ belonging to its zero charge state (point of zero charge, $\mathrm{PZC}$ ) in aqueous medium [8-12]. The titration experiments and evaluation of data comprise $\mathrm{pH}$ measurement, acid-base titration, calculation of proton concentration in the aqueous phase of the oxide dispersions, calculation of net proton consumption and converting proton consumption to surface charge density. All these methods are in principle well established, yet published $\mathrm{pH}$ PZC values ( $\mathrm{pH}$ of the point of zero charge) of chemically identical metal oxides scatter significantly [9, 13-15]. The numerous values listed in the collections of Kosmulski [e.g., 14,15] are not critically evaluated, while not too much, but carefully selected data can be found in [11]. PZC values characterize the protonation/deprotonation constants of the 
This is a PDF file of an unedited manuscript that has been accepted for publication. Final edited form is published in Colloids and Surfaces A, 2012, 414:302-313. http://dx.doi.org/10.1016/j.colsurfa.2012.08.027

interfacial equilibrium processes taking place at the $\mathrm{SOH}$ groups of oxide surfaces in acidic/alkaline solutions, and must be unique for chemical compounds. Small deviations because of the crystal structure and surface energy conditions are acceptable, but the several $\mathrm{pH}$ units wide range of published PZCs (for example, $\sim 3.5$ to $\sim 10.5$ for $\mathrm{Al}_{2} \mathrm{O}_{3}$ or $\sim 2$ to $\sim 9$ for $\left.\mathrm{TiO}_{2}[16]\right)$ is not chemically justifiable.

Each separate step in the titration experiments and data evaluation can yield smaller or larger deviation of PZC. Several examples are the following.

i) $\mathrm{pH}$ measurement. The notional definitions $\mathrm{pH}=-\log \left(\mathrm{a}_{+}\right)$or $\mathrm{pH}=-\log \left(\mathrm{c}_{+}\right)$are commonly used to calculate $\mathrm{a}_{\mathrm{H}+}$ and $\mathrm{c}_{\mathrm{H}+}$, while the measured $\mathrm{pH}$ values are related to the acidity function, not directly to proton activity or proton concentration as clearly stated in the IUPAC Recommendation [17] besides others [18, 19], and shortly summarized in Supplementary Material (S1). In addition, the conversion of $\mathrm{pH}$ to $\mathrm{a}_{\mathrm{H}+}\left(\right.$ or $\left.\gamma_{\mathrm{H}+} \mathrm{c}_{\mathrm{H}+} / \mathrm{c}_{\mathrm{H}+}{ }^{0}\right)$ suffers from various errors in $\mathrm{pH}$ scale, as well as from the lack of knowledge of the ionic composition and ionic strength of the $\mathrm{pH}$ standards (buffer solutions).

ii) Acid-base titration. Different titration kinetics, i.e., slow, fast or equilibrium titration, can lead to different results. Experiments can be performed with or without background electrolyte titrations [10].

iii) Calculation of proton concentration. The value of $\mathrm{c}_{\mathrm{H}+}$ can be assessed from the measured $\mathrm{pH}$ value [20-23], from the volume of titrant of known concentration at the given $\mathrm{pH}$ [24-29], using both measured $\mathrm{pH}$ and titrant volume [10], or cell potential and titrant volume [30]. The first two procedures require background electrolyte titrations, the last two can be applied in the absence of them, and the last one avoids even $\mathrm{pH}$ buffer calibration. In the "titrant volume" method, the assumption is that the same $\mathrm{pH}$ means the same proton concentration in the absence and the presence of colloid particles.

iv) Conversion of net proton consumption to surface charge. In fact, the acid-base consumption can only be measured. The basic conditions, under which the direct conversion is possible (through the Faraday constant), are the presence of indifferent background electrolyte (obeying only physical interaction at electrified interface), and the absence of any specific ions (involved in chemical interaction with surface sites, too) and any processes with proton participation except for surface charging. Most practical dispersions fail these conditions, and so the effects of various interferences must be taken into account. Specific considerations are needed in each individual titration to detect and eliminate the interferences with surface charging.

Charge state of oxide nanoparticles is frequently characterized by electrokinetic (or zeta) potential measurements as well $[31,32]$. Electrokinetic measurements as well as mass titration [20] or colloidal stability experiments are frequently used to check the point of zero charge. However, zeta potential (representing "net electric charge" [33]) is the result of many factors; one of them is surface charge density. The values of zeta potential alone cannot be used as guiding parameter in designing preparation routes of nanocomposites or in tracking the fate of nanoparticles in the environment. On the contrary, the exact knowledge of the intrinsic surface charging behaviour obtained from the correctly performed potentiometric acid-base titrations is appropriate for reliable handling of oxide nanoparticles.

The aim of this paper is to present in detail the steps of our practicable protocol, which has been worked out to obtain inherent values of surface charge density and PZC. Internal tests, incorporated in order to eliminate interferences with $\mathrm{pH}$ measurement and surface protonation equilibria, are also discussed. We have applied this protocol successfully for a large number of difficult oxide samples with interferences from many different sources (see the reference list in Supplementary Material (S2)), but the background and examples of the operation are published for the first time. 
This is a PDF file of an unedited manuscript that has been accepted for publication. Final edited form is published in Colloids and Surfaces A, 2012, 414:302-313. http://dx.doi.org/10.1016/j.colsurfa.2012.08.027

\section{Theoretical background}

The standard Gibbs free energy of surface charge formation $\left(\Delta \mathrm{G}^{\varnothing}\right)$ is composed of the chemical part $\left(\Delta \mathrm{G}^{\varnothing}\right.$ chem $)$ determined by interfacial chemical reactions

(protonation/deprotonation of SOH groups) and the electrostatic part $\left(\Delta \mathrm{G}^{\varnothing}{ }_{\text {el }}\right)$ determined by development of electrostatic potential at the interface in the process of

protonation/deprotonation $[10,11]$ :

$$
\Delta \mathrm{G}^{\varnothing}=\Delta \mathrm{G}^{\varnothing} \text { chem }+\Delta \mathrm{G}^{\varnothing} \text { el. }
$$

The total free energy is expressed by the apparent ionization constant $\left(\mathrm{K}_{\mathrm{app}}\right)$

$$
\Delta \mathrm{G}^{\varnothing}=\mathrm{RT} \ln \mathrm{K}_{\mathrm{app}},
$$

its chemical part by the intrinsic ionization constant $\left(\mathrm{K}_{\text {int }}\right)$

$$
\Delta \mathrm{G}^{\varnothing} \text { chem }=\mathrm{RT} \ln \mathrm{K}_{\text {int }} \text {, }
$$

and its electrostatic part by the resulting potential difference $\left(\Psi_{0}\right)$

$$
\Delta \mathrm{G}_{\mathrm{el}}^{\varnothing}=\Delta \mathrm{z} F \Psi_{0}
$$

In the above equations $\mathrm{R}$ is the gas constant, $\mathrm{T}$ is absolute temperature, $\Delta \mathrm{z}$ is the change in the charge of surface groups (+/- 1 in the case of protonation/deprotonation) and $\mathrm{F}$ is the Faraday constant.

Unfolding eq. (1) and inserting the expressions for the thermodynamic equilibrium constants $\mathrm{K}_{\text {app }}$ and $\mathrm{K}_{\mathrm{int}}$, the Nernst equation is obtained, which describes the dependence of potential difference $\Psi_{0}$ on the activity of potential determining ions $\left(\mathrm{H}^{+}\right.$for oxides) at the actual state in reference to the state of PZC $\left(\mathrm{a}_{\mathrm{H}+}-\mathrm{a}_{\mathrm{H}+\mathrm{PZC}}\right)$ :

$$
\Psi_{0}=(\mathrm{RT} / \Delta \mathrm{zF}) \cdot\left(\ln \mathrm{a}_{\mathrm{H}+}-\ln \mathrm{a}_{\mathrm{H}+, \mathrm{PZC}}\right) \text {. }
$$

Nernst equation, generally used for redox reactions in electrochemical cells [34], is considered valid for the $\mathrm{pH}$-electrodes and for oxide surfaces as well [10, 11]. Kallay and coauthors have proven both theoretically and experimentally the linear dependence of $\psi_{0}$ on $\mathrm{pH}$, the slope being significantly lower than Nernstian for metal oxide interfaces [35]. The universally applied form of the Nernst equation uses $\mathrm{pHs}$ instead of proton activities:

$$
\mathrm{E}=-2.303(\mathrm{RT} / \Delta \mathrm{zF}) \cdot\left(\mathrm{pH}-\mathrm{pH}_{\mathrm{ref}}\right) \text {, }
$$

for $\mathrm{pH}$ electrodes (where $\mathrm{E}$ is cell potential and $\mathrm{pH}_{\text {ref }}$ is the $\mathrm{pH}$ corresponding to $\mathrm{E}=0$ ), and

$$
\Psi_{0}=-2.303(\mathrm{RT} / \Delta \mathrm{zF}) \cdot(\mathrm{pH}-\mathrm{pH} \mathrm{PZC})
$$

for oxide surfaces [11]. The latter expression validates $\mathrm{pH}_{\mathrm{PZC}}$ as the natural internal reference state of oxides with respect to surface charging. The substitution of $\mathrm{pH}$ for $\ln \mathrm{a}_{\mathrm{H}+}$ is correct, strictly speaking, only when the measured $\mathrm{pH}$ can be traced back to proton activity. IUPAC [17] provides the opportunity of tracing back $\mathrm{pH}$ experimentally to aH+. Thus, Nernst equation dictates the linear dependence of $\mathrm{E}$ not only on $\mathrm{ln} \mathrm{a}_{\mathrm{H}+}$ but also on $\mathrm{pH}$. Customary $\mathrm{pH}$ buffer calibrations translate measured cell potentials into universal $\mathrm{pH}$ values $(\mathrm{E}=$ const $\cdot \Delta \mathrm{pH})$ and by this the $\mathrm{pH}$ scale is standardized.

Surface charge development occurs by ion transfer from the aqueous phase. Surface charge density of oxides formed by proton transfer $\left(\sigma_{0, \mathrm{H}}\right)$ can be defined through the net surface proton excess [36]:

$$
\sigma_{0, \mathrm{H}}=\mathrm{F}\left(\Gamma_{\mathrm{H}+}-\Gamma_{\mathrm{OH}-}\right)
$$

Determination of surface excess amount or Gibbs excess $\left(\Gamma_{\mathrm{H}+}-\Gamma_{\mathrm{OH}-}\right)$ in dilute solutions [37] requires the knowledge of accurate concentrations of $\mathrm{H}^{+}$and $\mathrm{OH}^{-}$over a broad $\mathrm{pH}$ range.

Therefore, a second calibration has to be performed in each background electrolyte in order to derive proton concentrations from the measured $\mathrm{pH}$ values $\left(10^{-\mathrm{pH}}=\right.$ const $\left.\cdot \mathrm{c}_{+}\right)$. If the $\mathrm{pH}$ and $\mathrm{C}_{\mathrm{H}+, \mathrm{OH}-\mathrm{scales}}$ are both calibrated, then the accurate characterization of oxide surface charging by potentiometric acid-base titration becomes practicable in principle. Therefore, it is worth testing this double calibration method in practice. 
This is a PDF file of an unedited manuscript that has been accepted for publication. Final edited form is published in Colloids and Surfaces A, 2012, 414:302-313. http://dx.doi.org/10.1016/j.colsurfa.2012.08.027

\section{Materials and methods}

Aluminium oxide $\left(\gamma-\mathrm{Al}_{2} \mathrm{O}_{3}\right.$ Degussa $\mathrm{C}$, "original alumina", particle diameter $(\mathrm{d})$ is 13 $\mathrm{nm})$ and titanium dioxide $\left(\mathrm{TiO}_{2} \mathrm{P} 25\right.$, "original titania", $\left.\mathrm{d}=21 \mathrm{~nm}\right)$ were products of Degussa AG. Zinc oxide (ZnO NANOX200, "ZnO", d = $60 \mathrm{~nm}$ ) was obtained from Elementis Specialties, USA. The titrations of the nanoparticles have been performed in $\mathrm{KCl}$ or $\mathrm{KNO}_{3}$ background electrolytes of $0.005,0.05$ and $0.5 \mathrm{M}$ concentrations. Separate background electrolyte titrations in $\mathrm{NaCl}$ were also performed to demonstrate the behaviour of the electrodes in different electrolytes. Titania and alumina are flame hydrolysis products of the corresponding metal chlorides. Purified samples (heat-treating at $1000{ }^{\circ} \mathrm{C}$ of alumina and extensive washing of titania) were also titrated. The titrants $\mathrm{KOH}, \mathrm{NaOH}, \mathrm{HNO}_{3}$ and $\mathrm{HCl}$ and the electrolytes were analytical grade products (Reanal Private Ltd, Hungary). Purified water from MilliQ RG system (Millipore) was used after intensive boiling for perfect $\mathrm{CO}_{2}$ removal. Carbonate-free base solutions were prepared after rinsing the $\mathrm{KOH}$ or $\mathrm{NaOH}$ pellets three times with $\mathrm{CO}_{2}$-free purified water. The absence of carbonate was tested with hydrazine sulphate (analytical grade, Reanal). The base titrants were standardized using benzoic acid (analytical grade, Reanal) solution, and they were used right away to standardize acid titrants. Secondary standard buffer solutions of Radelkis Ltd. (Hungary) of $\mathrm{pH}\left(25^{\circ} \mathrm{C}\right)=2.07 \pm 0.03$ $(\mathrm{RK}-21), \mathrm{pH}\left(25^{\circ} \mathrm{C}\right)=7.10 \pm 0.03(\mathrm{RK}-71)$ and $\mathrm{pH}\left(25^{\circ} \mathrm{C}\right)=9.31 \pm 0.03$ (RK-91) were used for buffer calibrations. All titrations were carried out under programmed stirring and $\mathrm{N}_{2}$ bubbling (Nitrogen 4.5 from Messer, min. $99.995 \%$ purity, no $\mathrm{CO}_{2}$ content). Washing bottle containing $\mathrm{CO}_{2}$ free MilliQ water was used to wet the $\mathrm{N}_{2}$ gas and minimize volume errors due to bubbling.

The automatic titration setup comprises a sample holder, a magnetic stirrer, $\mathrm{N}_{2}$ gas inlet, acid and base burettes (Metrohm, Dosimat 665), a combined pH glass electrode (OP0808P of Radelkis Ltd, Hungary) and a high precision potentiometer with $\mathrm{pH}$ preamplifier (made in Department of Experimental Physics, University of Szeged, Hungary). The electrodes were stored, cleaned and activated according to the instructions of the manufacturer. The accuracy of $\mathrm{mV}$ readings of the potentiometer is $\pm 0.01 \mathrm{mV}$. Homemade software (Gimet-1) was used to control the titration process, applying one of the two optional titration methods: linear or equilibrium method. The temperature was held constant $(25 \pm 0.5$ ${ }^{\circ} \mathrm{C}$ ) during titrations. The effect of liquid junction potentials (ljp) have not been accounted for in the titrations because i) their value is constant at the fixed ionic strength of the experiments and ii) the ljp in the background electrolytes and the dispersions cancel one another in the course of the evaluation.

For $\mathrm{pH}$ calibrations, five separate, drift-free $\mathrm{mV}$ readings were averaged. Each single $\mathrm{mV}$ reading was obtained in a sequence of stirring $(5 \mathrm{sec})$, relaxation $(5 \mathrm{sec})$ and sampling (5 sec). During stirring $\mathrm{N}_{2}$ was bubbled through the solution. During relaxation and sampling the stirring was stopped and $\mathrm{N}_{2}$ flow was directed above the solution surface. The electrode performance was considered acceptable, if the slope of the $\mathrm{mV}$ vs. $\mathrm{pH}$ plot was not smaller than $95 \%$ of the Nernstian [38]. The electrodes were calibrated in pH buffers (secondary standards) every day prior to titrations.

Proton concentration calibrations were measured in $50 \mathrm{~mL}$ of background electrolyte solutions of $0.005,0.05$ and $0.5 \mathrm{M}$ concentration. $1 \mathrm{~mL}$ of $0.1 \mathrm{M}$ acid titrant was added to the electrolytes and bubbled with $\mathrm{N}_{2}$ for $15 \mathrm{~min}$ before the titration with base. Two subsequent titrations were performed continuously, "up" titration with $0.1 \mathrm{M}$ base titrant and "down" titration back to low $\mathrm{pH}$ with the acid titrant. The designations "up" and "down" express the direction of the $\mathrm{pH}$ change. Standard volumes $(0.04 \mathrm{~mL})$ of the titrants were added in $\sim 20 \mathrm{~s}$ intervals within the range of $\mathrm{pH}$ between $\sim 2.5$ and $\sim 11.5$, using the linear titration method. The single $\mathrm{mV}$ readings were obtained the same way as in the $\mathrm{pH}$ buffer calibrations. 
For the dispersion titrations $0.5-1 \mathrm{~g}$ of oxide samples in $50 \mathrm{~mL}$ of background electrolyte solutions were prepared. Prior to titrations, the dispersions were stirred and bubbled with $\mathrm{N}_{2}$ for $15-20$ min to equilibrate and remove dissolved and adsorbed $\mathrm{CO}_{2}$. Titrations started either from the natural $\mathrm{pH}$ of the suspensions (alumina and $\mathrm{ZnO}$ ), or from lower $\mathrm{pH}$ (titania) achieved by addition of a known amount of acid. Low $\mathrm{pH}$ promotes carbonate removal, but its use is limited by acid dissolution of some solids. Single $\mathrm{mV}$ readings were obtained the same way as in the buffer and background electrolyte measurements. Titrant addition was controlled by a feedback mechanism, using adjustable criteria to reach equilibrium state and a predetermined size of $\mathrm{pH}$-steps. The equilibrium criterion was chosen to allow a maximum drift of $0.0002-0.0005 \mathrm{pH} / \mathrm{sec}$ during $45 \mathrm{sec}$, the duration of three consecutive $\mathrm{mV}$ readings, i.e., less than $0.009-0.0225 \mathrm{pH}$ units for a single measured $\mathrm{pH}$ value. In case the $\mathrm{pH}$ drift exceeded the equilibrium criterion, the sequence of stirring-waiting-sampling ( $45 \mathrm{sec}$ ) has been started again and the new value of $\mathrm{pH}$ drift was calculated. The next titrant dose was added only after the equilibrium criterion has been fulfilled. The waiting time between titrant additions was limited at $10 \mathrm{~min}$ to exclude the possible effect of $\mathrm{pH}$-drifting artefacts. It is necessary to achieve equilibrium in each step of the titrations, since only equilibrium processes characterize truly the interface and only equilibrium data can be used for further thermodynamic analysis. While proton association/dissociation processes are fast in the aqueous solutions, at the interface these may get slow due to electrostatic, kinetic or steric hindrance weakening the driving force of protonation/deprotonation. The equilibrium character of the titrations was tested by measuring reversibility of the up and down titrations. The $\mathrm{pH}$ step was set to 0.3 units. Because of the small size of the oxide nanoparticles, sediment formation was not observed during the titrations, thus, the suspension effect $[39,40]$ did not occur.

The target uncertainty of the titrations and calculation procedure is expressed as the deviation of the values of cip and pzc, estimated as $\pm 0.1 \mathrm{pH}$ units. The main contributors are associated with the uncertainties in buffer solution $\mathrm{pH}$, electrode $\mathrm{mV}$ readings and volume errors in the solution preparations and dosing of titrant.

\section{Results}

\subsection{Proton concentration calibrations}

Proton concentration calibrations were measured for each background electrolyte concentration. The lowest electrolyte concentration was chosen as $0.005 \mathrm{M}$, ensuring that the ionic strength (I) remained practically constant during the titrations. At the frequently used $0.001 \mathrm{M}$ concentration, for example, the ionic strength changes by $100 \%$ during titrations between $\mathrm{pH} 3$ and 11 , while at $0.005 \mathrm{M}$ the same change is only $20 \%$. Unfortunately, we also applied $0.001 \mathrm{M}$ in our earliest works, which we have revised later on.

The actual proton concentration $\left(\mathrm{C}_{\mathrm{H}+, \mathrm{OH}-} \equiv \mathrm{C}_{\mathrm{H}+}-\mathrm{COH}_{-}\right)$was calculated at each titrant dose according to the equation:

$$
\mathrm{c}_{\mathrm{H}+, \mathrm{OH}-}=\left(\mathrm{c}_{\mathrm{H}+, 0} \cdot \Sigma_{\mathrm{i}} \mathrm{V}_{\mathrm{H}+\mathrm{i}}-\mathrm{cOH}-, 0 \cdot \Sigma_{\mathrm{i}} \mathrm{VOH}_{-, \mathrm{i}}\right) /\left(\mathrm{v}_{0}+\Sigma_{\mathrm{i}} \mathrm{V}_{\mathrm{H}+, \mathrm{i}}+\Sigma_{\mathrm{i}} \mathrm{VOH}_{-, \mathrm{i}}\right),
$$

where $\mathrm{c}_{+}, 0$ and $\mathrm{COH}_{-, 0}$ are the concentrations of the acid and base titrants, $\mathrm{vH}_{+, \mathrm{i}}$ and $\mathrm{VOH}_{-, \mathrm{i}}$ are the volumes of the $\mathrm{i}$-th dose of acid and base titrants and $\mathrm{v}_{0}$ is the volume of the background electrolyte.

The values of $\mathrm{pH}$ in the acidic part $\left(\right.$ at $\left.\left(\mathrm{c}_{\mathrm{H}}-\mathrm{cOH}_{-}\right)>0\right)$ and $\mathrm{pOH}$ in the basic part (at $\left.\left(\mathrm{c}_{\mathrm{H}+}-\mathrm{c}_{\mathrm{OH}-}\right)<0\right)$ of the titration curves were calculated from the measured cell potentials using the buffer calibration functions $E_{\text {cell }}=f\left(\mathrm{pH}_{\text {buffer }}\right)$ and $\mathrm{pK}_{\mathrm{w}}=14$ (at $\left.25^{\circ} \mathrm{C}\right)$. The proton concentration calibrations are the plots of $10^{-\mathrm{pH}}$ and $10^{-\mathrm{pOH}} \mathrm{Vs}$. $\left(\mathrm{c}_{\mathrm{H}+}-\mathrm{COH}_{-}\right)$, as presented in Fig. 1. The math behind the plots is similar to that of the well-known Gran method [41] derived for equivalence point determination in titrations of weak acids and bases. The Gran 
functions, $\mathrm{V} \cdot 10^{-\mathrm{pH}}$ and $\mathrm{V} \cdot 10^{-\mathrm{pOH}} \mathrm{vs}$. $\mathrm{V}_{\text {titrant }}\left(\mathrm{V}\right.$ is the total volume and $\mathrm{v}_{\text {titrant }}$ is the volume of the titrant solution) are linear only either before or after the equivalence point. The plots of $10^{-}$ ${ }^{\mathrm{pH}}$ and $10^{-\mathrm{pOH}}$ vs. ( $\mathrm{C}_{\mathrm{H}+}-\mathrm{COH}$-) of the titrations of strong acids and bases are linear both before and after the equivalence point. The exact concentration of the base titrant $\left(\mathrm{COH}_{-}, 0\right)$ is determined in every calibration experiment by finding the value of $\Sigma_{\mathrm{i}} \mathrm{VOH}_{-, \mathrm{i}}$ at $\left(\mathrm{c}_{\mathrm{H}+}-\mathrm{COH}_{-}\right)=$ 0 . The concentration of the acid titrant is determined after the preparation, and considered as constant for sufficiently long period.

The acidic and basic sides of the titrations are clearly separated in the proton concentration calibration plots (Fig. 1). The slopes, $S_{\mathrm{a}}$ in the acidic and $\mathrm{S}_{\mathrm{b}}$ in the basic sides, represent the actual response of the electrode to proton and hydroxyl concentrations. We have designated these slopes in our previous publications [42-45] as actual activity coefficients. $S_{a}$ and $S_{b}$ vary clearly with ionic strength.

The electrode response is nearly symmetrical in $\mathrm{KCl}$ (Fig. 1a), but not in $\mathrm{NaCl}$ (Fig. 1b). In the case of $\mathrm{KCl}$ the positive and negative cell potentials are depressed symmetrically $\left(10^{-\mathrm{pH}}\right.$ and $10^{-\mathrm{pOH}}$ in Fig. 1a) by increasing ionic strength. The activity coefficients of proton vary with ionic strength, which can explain the decrease in the measured cell potentials. In addition, non-specific (physical) charge screening effect plays a role, also depressing the surface potential (and cell potential) with increasing I. The effect is symmetric because there is no specific effect of either $\mathrm{K}^{+}$or $\mathrm{Cl}^{-}$, to the surface of the glass electrode. On the contrary, $\mathrm{Na}^{+}$has a high chemical affinity to the glass electrode commonly known as sodium error, and its specific (chemical) adsorption increases the positive cell potential (acidic side) and decreases the negative cell potential (basic side), seen in Fig. 1b. The ion specific effect dominates over charge screening. Consequently, the varying slopes reflect the sensitivity of the given electrode to protons (or hydroxyls) under the actual solution conditions. Note that the indifferent or specific feature of the background electrolyte ions affects the protonequilibria of the sensor system (glass electrode) fundamentally, in parallel with its wellknown effect on the protonation of the solid surface (metal oxides here).

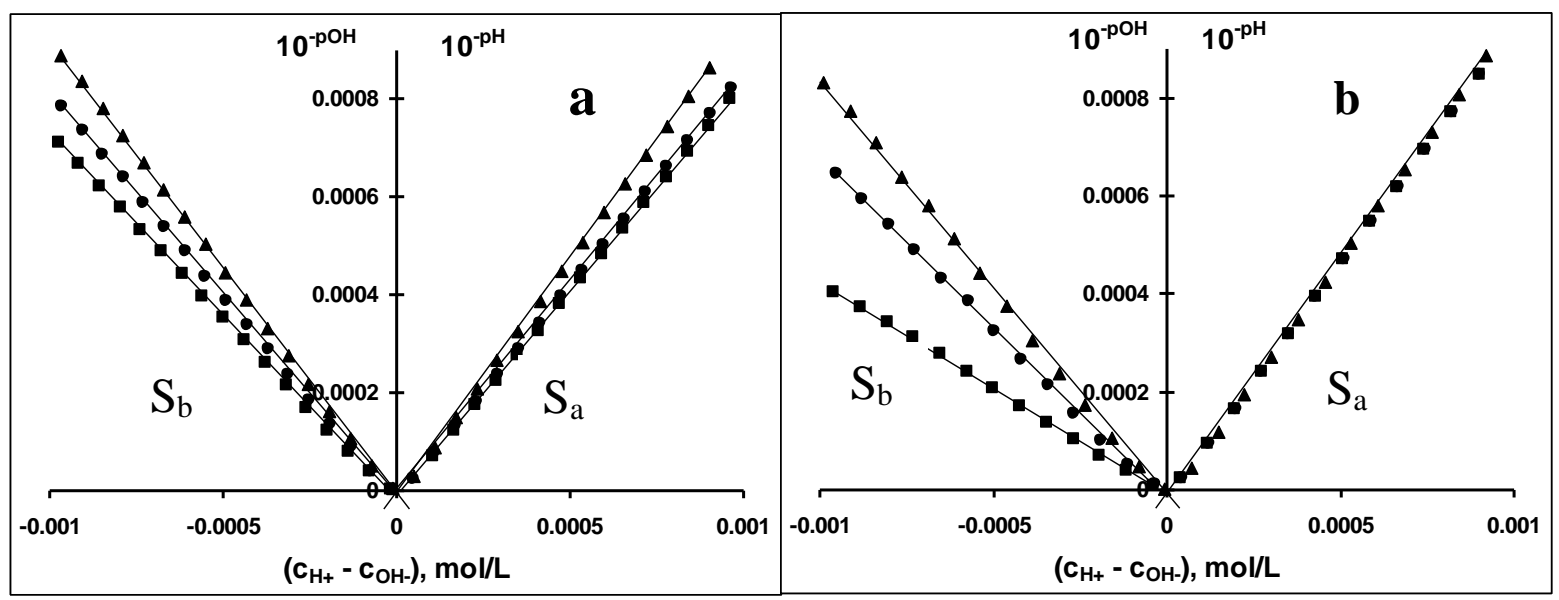

Fig. 1. Proton concentration calibration plots in $\mathrm{KCl}$ (a) and $\mathrm{NaCl}$ (b) electrolytes $(\boldsymbol{\Delta}-0.005$ $\mathrm{M}, \bullet-0.05 \mathrm{M}, \boldsymbol{\square}-0.5 \mathrm{M})$.

In Fig. 2 the most typical deviations from linearity are demonstrated in proton concentration calibration plots. The plots in Fig. 2a have been measured with the same, originally perfectly responding electrode, using for prolonged time especially in $\mathrm{NaCl}$ solutions without regular activations. Flattening around neutral $\mathrm{pH}$ as it is seen in Fig. $2 \mathrm{a}$, is an extremely frequent deviation even besides proper handling and activation, caused by specific fouling of the electrode. 
This is a PDF file of an unedited manuscript that has been accepted for publication. Final edited form is published in Colloids and Surfaces A, 2012, 414:302-313. http://dx.doi.org/10.1016/j.colsurfa.2012.08.027

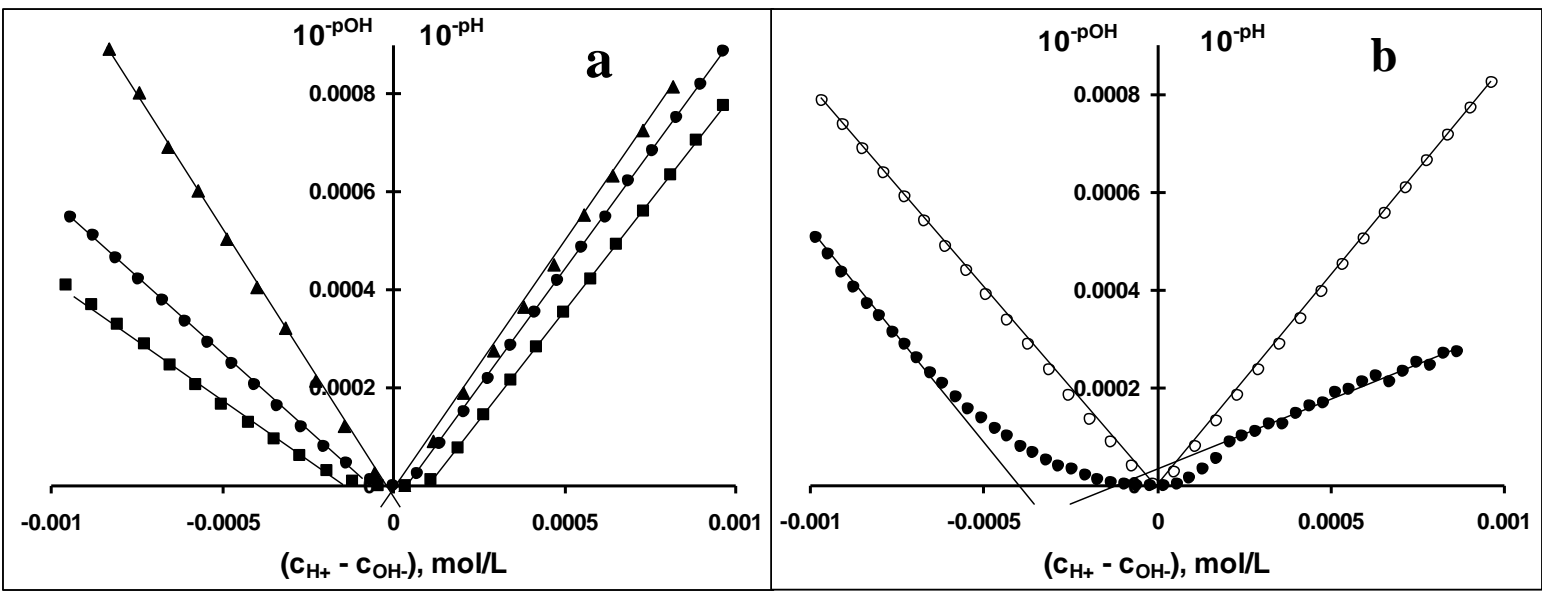

Fig. 2. Gradual change in the shape of proton concentration calibration plots in $0.1 \mathrm{M} \mathrm{NaCl}$ after working with colloid suspensions for prolonged period of time, $\boldsymbol{\Delta}-$ freshly activated electrode, - after 2 months, - after 3 months (a). Proton concentration calibration plots of a malfunctioning electrode $(\bullet)$, and a correctly responding electrode $(O)$, in $0.05 \mathrm{M} \mathrm{KCl}$ solution (b).

Fig. $2 b$ represents the performance of an electrode that could not be regenerated by activation. In practice, the electrode performance is correct when the proton concentration calibration plots are linear as in Fig. 1, so that activation and cleaning must be repeated until the correct response is achieved.

Non-linear response in the background electrolytes precludes high quality titrations in the sample dispersions as well. Malfunctioning of the electrodes is not always detectable in the $\mathrm{pH}$ buffer calibrations. For example, the slope of the buffer calibration of the electrode in Fig. 2a was $99.9 \%$ of the Nernstian slope $\left(\mathrm{R}^{2}=0.999999\right)$ and that of the malfunctioning electrode in Fig. 2b (filled symbols) was $97.8 \%$ of the Nernstian $\left(\mathrm{R}^{2}=0.999996\right)$. The bad performance could not be suspected from the buffer calibration alone; because any slope better than $95 \%$ of the Nernstian is acceptable according to the official user guides (e.g., [38]). The examples in Fig. 2 draw attention to the errors in $\mathrm{pH}$ measurements, the detection and elimination of which are only possible if background electrolyte titrations are performed and checked for linearity.

\subsection{Surface charge vs. $p H$ functions}

Our procedure of determination of surface charge vs. $\mathrm{pH}$ functions is essentially model-independent. Instead of the notional definitions $\mathrm{pH}=-\log \mathrm{a}_{\mathrm{H}+}$ or $\mathrm{pH}=-\log \mathrm{c}_{\mathrm{H}+}$ and the extra-thermodynamic activity coefficient $\gamma_{\mathrm{H}+}$, commonly applied in literature, we use only material balance equations and assume that proton concentrations change only due to surface protonation/deprotonation. This model-independent approach relies fully on the double calibration method, which enables us to assign exact proton concentrations to the measured cell potentials in the oxide dispersions via the plots of proton concentration calibration. It is useful to make clear distinction between $\mathrm{pH}$ buffer calibrations and proton concentration calibrations. In the first, the response of the electrode to the universal $\mathrm{pH}$ scale is measured, ensuring the uniformity of the experimental $\mathrm{pH}$ axes among titrations performed at different times and different places. In the second, the response of the electrode to the known proton concentrations is measured, ensuring proton concentration determination in the sample solutions, i.e., in the medium of the oxide dispersions.

Surface charge calculation is based on the well-known model of adsorption from dilute solutions, introduced by D. H. Everett [37]. According to the model, the specific surface 
excess amount $n^{\sigma}$ of solute $i$ is given by the difference in the initial $\left(c_{i, 0}\right)$ and equilibrium $\left(c_{i, e}\right)$ concentrations in the solution,

$$
\mathrm{n}_{\mathrm{i}}=\mathrm{V} \cdot\left(\mathrm{c}_{\mathrm{i}, 0}-\mathrm{c}_{\mathrm{i}, \mathrm{e}}\right) / \mathrm{m} \text {, }
$$

where $\mathrm{V}$ is the volume of the liquid phase and $\mathrm{m}$ is the mass of the adsorbent. The surface density of $i$ is $\Gamma_{i}=n^{\sigma_{i}} / a^{s}$, where $a^{s}$ is the specific surface area of the adsorbent. In case of surface protonation/deprotonation the net specific surface proton excess $\left(\Delta \mathrm{n}^{\sigma}{ }_{\mathrm{H}+\mathrm{OH}}\right)$ is the sum of the specific surface excess amounts of $\mathrm{H}^{+}$and $\mathrm{OH}^{-}$including sign: $\Delta \mathrm{n}_{\mathrm{H}+\mathrm{OH}-}=\mathrm{n}^{\sigma} \mathrm{H}_{+}-\mathrm{n}^{\sigma} \mathrm{OH}-$, where $n^{\sigma}{ }_{\mathrm{H}+}=n^{\sigma}{ }_{\mathrm{SOH} 2+}$ and $n^{\sigma}{ }_{\mathrm{OH}-}=n^{\sigma}{ }_{\mathrm{SO}}$. It is calculated at each point of the titration as

$$
\Delta \mathrm{n}^{\sigma}{ }_{\mathrm{H}+\mathrm{OH}-}=\mathrm{V}_{\text {total }} \cdot\left(\mathrm{c}_{\mathrm{H}+, \mathrm{OH}-, 0}-\mathrm{c}_{\mathrm{H}+, \mathrm{OH}-\mathrm{e}}\right) / \mathrm{m}_{\text {oxide. }} \text {. }
$$

The value of $\mathrm{C}_{\mathrm{H}+, \mathrm{OH}-0,0}$ results from titrant additions and it is calculated according to Eq. (9). The value of $\mathrm{c}_{\mathrm{H}+, \mathrm{OH}-\mathrm{e}}$ is calculated using the $\mathrm{S}_{\mathrm{a}}$ and $\mathrm{S}_{\mathrm{b}}$ factors (actual activity coefficients) from the proton concentration calibration plots (Fig. 1) as

$$
\mathrm{c}_{\mathrm{H}+\mathrm{OH}-\mathrm{O}}=10^{-\mathrm{pH}} / \mathrm{S}_{\mathrm{a}} \text { and } \mathrm{c}_{\mathrm{H}+, \mathrm{OH}-\mathrm{e}}=10^{-\mathrm{pOH}} / \mathrm{S}_{\mathrm{b}} \text {. }
$$

The net surface proton excess per unit area is $\Delta \mathrm{n}^{\sigma} \mathrm{H}_{+}, \mathrm{OH}-\mathrm{I} / \mathrm{a}_{\mathrm{s}}=\Delta \Gamma_{\mathrm{H}+, \mathrm{OH}-}=\Gamma_{\mathrm{H}_{+}}-\Gamma_{\mathrm{OH}}$. Since the determination of specific surface area available for protonation/deprotonation needs particular considerations in case of each oxides [46], here we use the values of net specific surface proton excess per unit mass of the oxide $\left(\Delta n^{\sigma}{ }_{H+, O H}, m m o l / g\right)$. Surface charge density can be

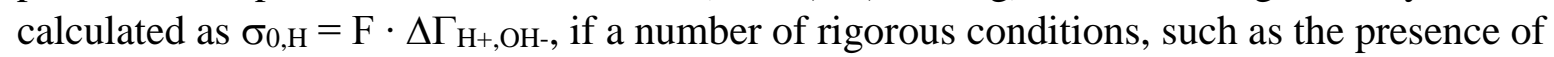
indifferent background electrolytes and the absence of any specific ions and any processes with proton participation except for surface charging as explained in the Introduction, are fulfilled. We do not calculate surface charge densities, as for our purposes it is sufficient to use the net specific surface proton excess $\left(\Delta \mathrm{n}^{\sigma}{ }_{\mathrm{H}+\mathrm{OH}-}\right)$ values.

Purified titania and alumina in indifferent electrolyte solutions are typical examples of ideal surface charging systems. The net specific surface proton excess vs. pH functions are shown Fig. 3a, and a typical reversibility test in Fig. 3b.

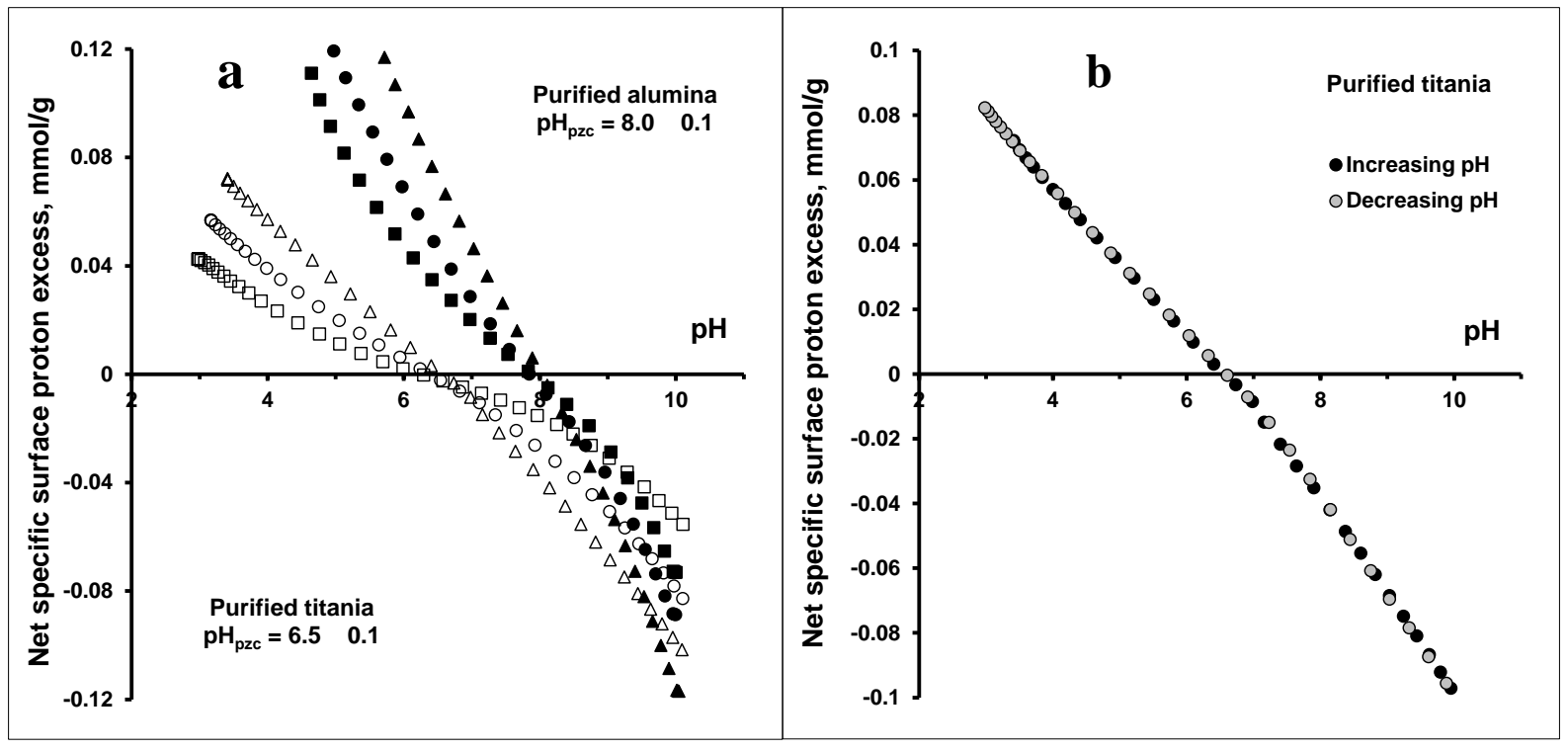

Fig. 3. Net specific surface proton excess vs. $\mathrm{pH}$ functions of purified titania (open symbols) and alumina (filled symbols) samples in $0.5(\boldsymbol{\bullet}, \triangle), 0.05(\bullet, \bigcirc)$ and $0.005(\boldsymbol{\square}, \square) \mathrm{M} \mathrm{KNO}_{3}$ (a). Reversibility test of purified titania, measured in subsequent up and down titrations in $0.05 \mathrm{M} \mathrm{KNO}_{3}$ (b).

Following characteristics of the ideal surface protonation/deprotonation processes can be observed in titrations of both titania and alumina in $\mathrm{KNO}_{3}$ : 
i) net proton consumption in up and down titrations are fully reversible (protons participate only in reversible reactions),

ii) the net specific surface proton excess curves at the three different background electrolyte concentrations intercept in a common intersection point (cip), at which net proton consumption is zero: cip = PZC (surface charge develops only in surface protonation/deprotonation reactions and protons do not participate in processes other than surface charging),

iii) moving away from $\mathrm{pH}$ PZC the three curves tend to "open" (surface charging is gradually screened by increasing concentration of indifferent electrolyte).

The primary results of titrations (i.e., the net proton consumption values) in such cases are directly the net specific surface proton excess values. In indifferent background electrolytes and in the absence of other proton consuming processes $\mathrm{pH}_{\text {cip }}=\mathrm{pH}_{\mathrm{PZC}}$ and cip $=\mathrm{PZC}$, since both the $\mathrm{x}(\mathrm{pH})$ and the $\mathrm{y}$ (net proton consumption and net surface proton excess) values of the two characteristic points coincide, the values of y being zero. However, any change in the above conditions may result in discrepancies between $\mathrm{pH}_{\mathrm{cip}}$ and $\mathrm{pH}$ PZC and also between cip and PZC. In the presence of proton consuming processes other than surface charging, the values of the ordinate shift, but the characteristic $\mathrm{pHs}$ of the process of protonation/deprotonation remain unchanged, i.e., cip $\neq \mathrm{PZC}$, but $\mathrm{pH}_{\mathrm{cip}}=\mathrm{pH}$ PZC. In the presence of specifically adsorbing ions (either constituents of the background electrolyte or not), both the values of $\mathrm{pH}$ and net proton consumption shift: $\mathrm{pH}_{\mathrm{cip}} \neq \mathrm{pH}$ PZC and cip $\neq \mathrm{PZC}$. The $\mathrm{pH}$ of the dispersions changes because of interfacial inner-sphere complex formation, e.g., for specific anion adsorption

$\mathrm{SOH}+\mathrm{A}^{-} \leftrightarrow \mathrm{SA}+\mathrm{OH}^{-}$(ligand exchange)

and the value of net surface proton excess changes because of surface charge neutralization due to electrostatic attraction, e.g., for specific anion adsorption

$\mathrm{SOH}_{2}^{+}+\mathrm{A}^{-} \leftrightarrow \mathrm{SA}+\mathrm{H}_{2} \mathrm{O}$ (charge neutralization).

Thus, inequality of $\mathrm{pH}_{\text {cip }}$ and $\mathrm{pH}_{\mathrm{PZC}}$ or that of cip and $\mathrm{PZC}$ indicates the non-ideal conditions of surface charging. The consequence of the above considerations is that PZC values can only be found under ideal experimental conditions, ensuring that $\mathrm{pH}_{\mathrm{cip}}=\mathrm{pH} \mathrm{HZC}_{\mathrm{C}}$ and cip=PZC.

In the knowledge of the accessible specific surface area and the value of $\Delta \mathrm{z}$ (effective charge transfer by surface protonation/deprotonation) the surface charge density can be calculated from the net specific surface proton excess values. Such experiments can also provide appropriate data for surface complexation model calculations [42].

Comparison of the titration results of original titania and alumina with the purified samples is presented in Fig. 4. The medium is $\mathrm{KCl}$ solution. $\mathrm{Cl}^{-}$impurities of 0.028 and 0.083 $\mathrm{mmol} / \mathrm{g}$ were present in the original titania and alumina samples, respectively, as determined by direct potentiometry and TOX measurements [42, 47]. The purified samples did not contain measurable amounts of $\mathrm{Cl}^{-}$. The y-axes in Fig. 4 are designated as "net proton consumption" because the cip values of the original samples are clearly not located at zero proton consumption. The consumed values at cip are $-0.023 \mathrm{mmol} / \mathrm{g}$ for titania and -0.08 $\mathrm{mmol} / \mathrm{g}$ for alumina, harmonizing with the analytically determined $\mathrm{Cl}^{-}$contents. The additional amount of base is used for neutralization of the free $\mathrm{HCl}$, present in the aqueous dispersions due to the hydrolysis of residual chloride of titanium or aluminium $\left(\mathrm{TiCl}_{4} \rightarrow\right.$ $\mathrm{Ti}(\mathrm{OH})_{4}+4 \mathrm{HCl}$ and $\left.\mathrm{AlCl}_{3} \rightarrow \mathrm{Al}(\mathrm{OH})_{3}+3 \mathrm{HCl}\right)[42,47]$. This means that net proton consumption is not solely due to surface protonation/deprotonation, but there is an extra base consumption, the amount of which can be detected at the cip in general. 
In the case of titania (Fig. 4a) $\mathrm{pH}_{\text {cip }}$ of the original sample is identical with $\mathrm{pH}$ PZC of the purified sample $(\mathrm{pH}=6.5 \pm 0.1)$. The whole set of curves is shifted by a constant amount, equivalent to the constant and additive base consumption of the hydrolysis product $\mathrm{HCl}$ from impurity. The points of zero salt effect (PZSE), cip in $\mathrm{KCl}$ and $\mathrm{PZC}$ in $\mathrm{KNO}_{3}$ (Fig. 3a), are located at the same $\mathrm{pH}$, suggesting that neither of the electrolyte ions $\mathrm{K}^{+}, \mathrm{NO}_{3}{ }^{-}$nor $\mathrm{Cl}^{-}$interact specifically with titania. Because of the absence of ion specificity, the net proton consumption vs. $\mathrm{pH}$ curves of the original titania can be shifted numerically, moving cip to PZC to obtain net specific surface proton excess vs. $\mathrm{pH}$ curves. This shifting of the curves relative to cip is commonly done in literature [26, 29, 48, 49], without checking experimentally the absence of specific ion (i.e., comparing with the titration of purified samples in indifferent electrolyte solution). The unambiguous proof of the ideal titration conditions resulting in net specific surface proton excess values is the coincidence of cip and PZC. This condition can be achieved experimentally, similarly as in the above example.

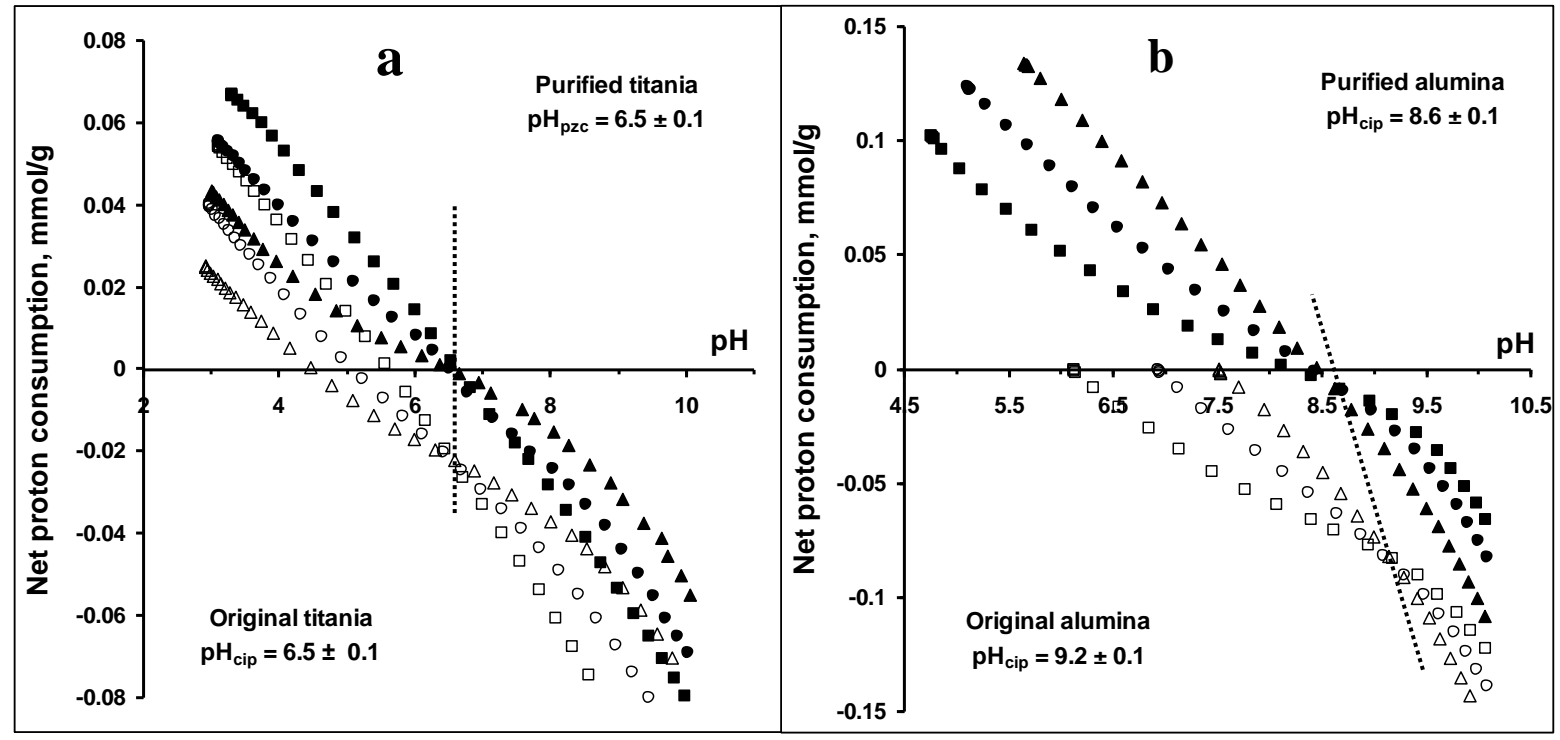

Fig. 4. Net proton consumption vs. pH functions of original (open symbols) and purified (filled symbols) oxide samples in $0.5(\boldsymbol{\Delta}, \triangle), 0.05(\bullet, \bigcirc)$ and $0.005(\boldsymbol{\square}, \square) \mathrm{M} \mathrm{KCl}$ : titania (a), alumina [42] (b).

Titration of alumina under the same conditions, however, revealed different behaviour. In $\mathrm{KNO}_{3}$, pH PZC of the purified sample is $8.0 \pm 0.1$ (Fig. 3a). In $\mathrm{KCl}$, there is no PZC, and $\mathrm{pH}_{\text {cip }}$ (PZSE) is shifted to $8.6 \pm 0.1$ (Fig. 4b, [42]). The net proton consumption at cip is $0.008 \mathrm{mmol} / \mathrm{g}$, but this is not consumed in $\mathrm{HCl}$ neutralization. If free acid were present, it would be neutralized in titration in $\mathrm{KNO}_{3}$ as well. The net proton consumption in cip results from the specific ion effect of $\mathrm{Cl}^{-}$present only in the background electrolyte. The latter is verified by the shift of $\mathrm{pH}_{\text {cip }}$ from 8.0 to 8.6, a generally acknowledged effect of anion specificity [11]. Original alumina has also cip ( $\mathrm{pH}_{\text {cip }}=9.2 \pm 0.1$ in Fig. $\left.4 \mathrm{~b}\right)$ in $\mathrm{KCl}$. Net proton consumption at cip is $-0.083 \mathrm{mmol} / \mathrm{g}$, which comprises the neutralization of free $\mathrm{HCl}$ and the specific effect of $\mathrm{Cl}^{-}$, present both as impurity and as background electrolyte. Thus, in the case of alumina in $\mathrm{KCl}$, the simple vertical shift of the net proton consumption vs. $\mathrm{pH}$ curves relative to cip cannot lead to PZC and net specific surface proton excess, because of specificity of $\mathrm{Cl}^{-}$. The commonly referred reasoning behind the practice of vertical shifting is that the exact value of surface charge cannot be determined experimentally. The primary results of the titrations are denoted generally as "relative charge" curves [50], suggesting by this that the entire amount of experimental proton consumption is linked to the charge 
formation, although by some undefined way. However, this is not the case. The deviation of net proton consumption from net specific surface proton excess is unequivocally the result of some other type of proton consuming processes, such as neutralization of free acid-base or specific adsorption of cations/anions. The effect of specific ion adsorption on net proton consumption can be eliminated only experimentally, by purification and by avoiding specific ion in the background electrolyte. The vertical shift of cip to PZC can only be applied in the absence of specific ion adsorption; otherwise, it does result in significant inaccuracy of PZC. Some problems with shifting cip to get PZC are noted by Sposito [24] as well. A clear example of misinterpretation of titration results is found in a paper by Rudzinsky et al [51]. The authors applied theoretical model calculations to a set of titration results of Mustafa et al [52], which did not provide surface charge data, but merely net proton consumption values. The $\gamma-\mathrm{Al}_{2} \mathrm{O}_{3}$ sample was dialysed to remove the chloride and sulphate impurities, but the absence of impurities after dialysis had not been proven by any independent analytical method (for example, direct potentiometry or TOX to determine $\mathrm{Cl}$ [42]). It is known that the efficiency of dialysis strongly decreases with increasing suspension concentration [42]. The titration results clearly show the presence of specifically adsorbing anions [11] and free acid in the suspension, and so net proton consumption differs from net specific surface proton excess, i.e., from surface charge. Rudznisky and co-workers used in fact net proton consumption data instead of surface charge, and arrived at the incorrect conclusion that $\mathrm{PZC} \neq$ $1 / 2\left(\mathrm{pK}^{\mathrm{int}}{ }_{\mathrm{a} 1}+\mathrm{pK}^{\mathrm{int}}{ }_{\mathrm{a} 2}\right)$, i.e., that PZC is not the intermediate $\mathrm{pH}$ between the intrinsic $\mathrm{pK}$ values of the two proton association equilibria. The latter is chemically inexplicable and contradicts the basic condition of PZC for oxides [10].

$\mathrm{pH}$-dependent dissolution of nanoparticles affects strongly the titration results as well, because the dissolution is faster due to their high specific surface area, and so its contribution to proton consumption probably comes out. Dissolution effects are demonstrated in Figs. 5 and 6 on the examples of alumina and $\mathrm{ZnO}$ in $\mathrm{KNO}_{3}$.

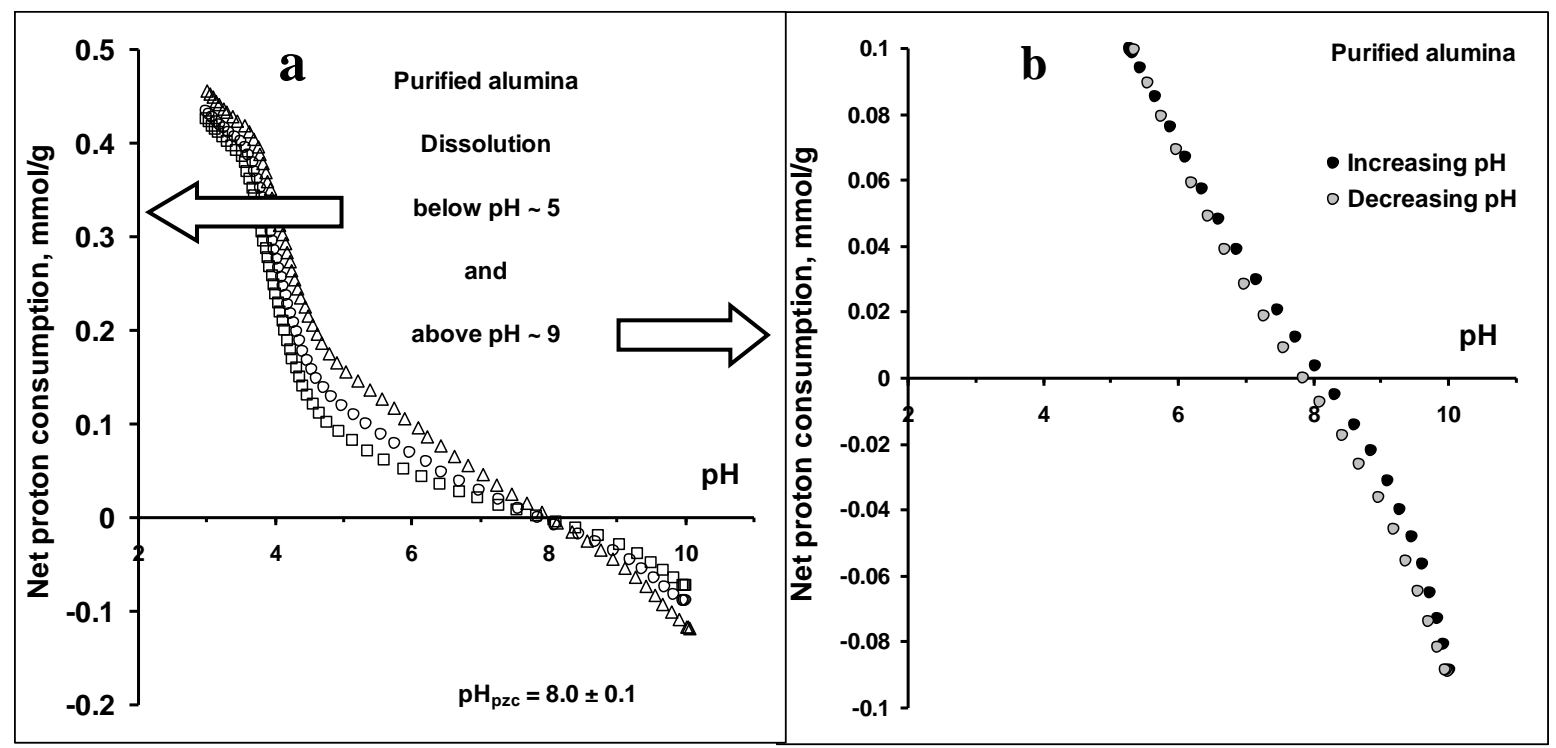

Fig. 5. Net proton consumption vs. pH functions of purified alumina in $0.5(\triangle), 0.05(O)$ and 0.005 ( $\square$ ) $\mathrm{M} \mathrm{KNO}_{3}$ (a). Reversibility test of purified alumina, measured in subsequent up and down titrations in $0.05 \mathrm{M} \mathrm{KNO}_{3}$ (b).

Titration of purified alumina in the $\mathrm{pH}$ range between 3 and 10 (Fig. 5) shows an abrupt increase in net proton consumption below $\mathrm{pH} \sim 5$, assigned to the dissolution of alumina, which we have proven analytically (by determining total $\mathrm{Al}$ concentration in the 
supernatants [42]). Unfortunately, similar changes are frequently assigned in the literature to surface sites with $\mathrm{pK}$ at the inflection point of the abrupt increase [53]. Critical analysis can help to justify or rule out the possibility of additional new pKs at the inflection points [54]. Surface charging is ionic strength dependent by virtue [55], thus the "opening" of the net proton consumption vs. $\mathrm{pH}$ curves at different ionic strengths is a prerequisite to consider net proton consumption as net specific surface proton excess. In Fig. 5a, the ionic strength dependence does not hold below $\mathrm{pH} \sim 5$, so that the increase cannot be assigned to surface charging. Alumina dissolution in the alkaline region is reflected by the hysteresis between the up and down curves (Fig. 5b) measured between pH 5 and 10. Dissolution-free, fully reversible net specific surface proton excess curves of purified alumina have been obtained by titrating within a restricted $\mathrm{pH}$ range, between 5 and 9 (not shown here).

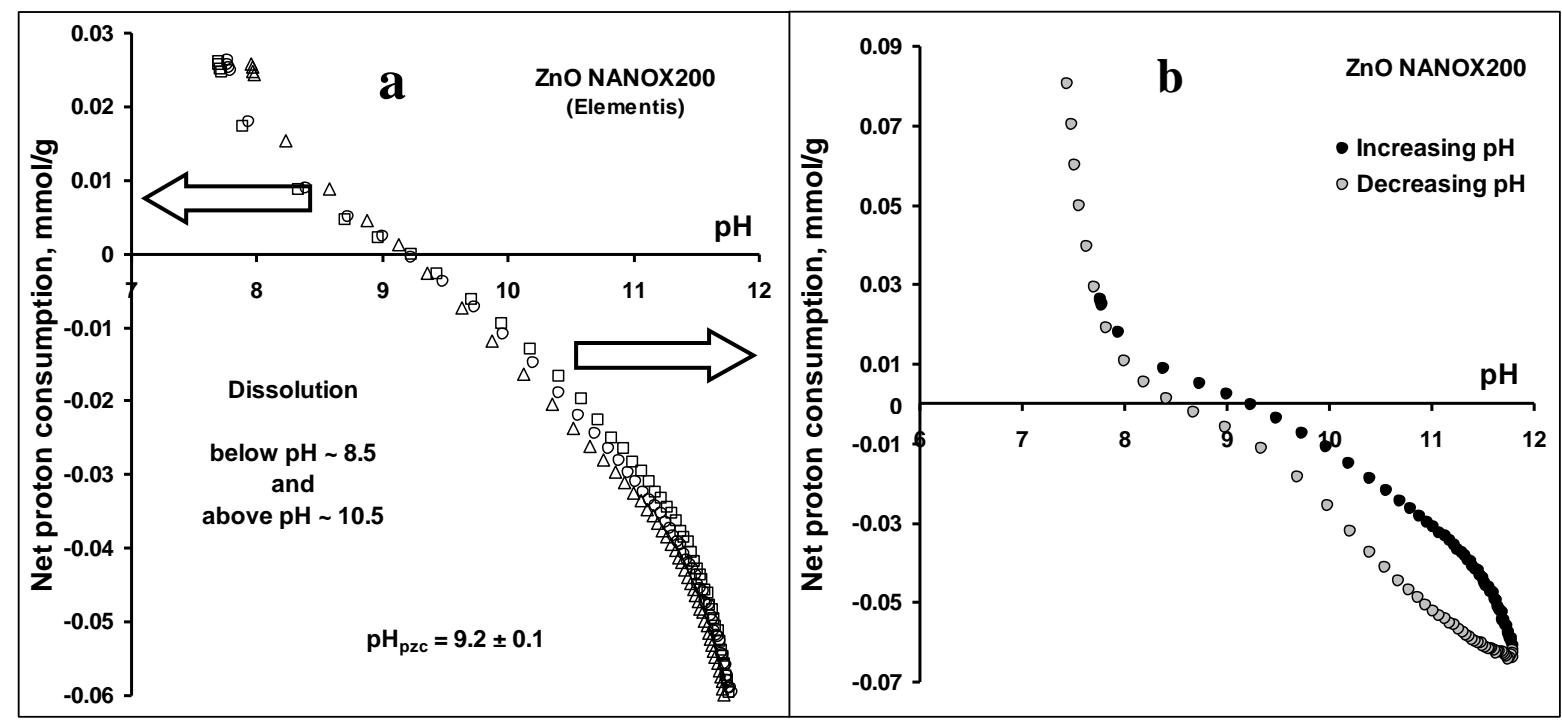

Fig. 6. Net proton consumption vs. pH functions of $\mathrm{ZnO}$ measured in $0.5(\triangle), 0.05(\bigcirc)$ and 0.005 ( $\square$ ) $\mathrm{M} \mathrm{KNO}_{3}[56]$ (a). Reversibility test of $\mathrm{ZnO}$, measured in subsequent up and down titrations in $0.05 \mathrm{M} \mathrm{KNO}_{3}$ (b).

The titration results of the nanosized $\mathrm{ZnO}$ sample are shown in Fig. 6a. $\mathrm{ZnO}$ is strongly soluble, reflected in the abrupt increase in net proton consumption both below $\mathrm{pH}$ $\sim 8.5$ and above $\mathrm{pH} \sim 10.5$. The ionic strength dependence of net proton consumption is very weak in the whole $\mathrm{pH}$ range. For most oxides, dissolution is not significant near PZC, so that pure surface protonation/deprotonation can be measured at least in the $\mathrm{pH}$ range of restricted solubility. For the $\mathrm{ZnO}$, the $\mathrm{pHs}$ of the onset of acidic and basic dissolution are very close to each other, thus solubility becomes significant near PZC as well. The considerable hysteresis between $\mathrm{pHs} \sim 7.5$ and $\sim 11.8$ (Fig. $6 \mathrm{~b}$ ) reveals serious interference from dissolution to surface charging. Narrowing the $\mathrm{pH}$-range, reversible titration cannot be achieved in the case of $\mathrm{ZnO}$, in contrast with the alumina sample. An unsolved hysteresis problem has been published recently by Adekola et al [57] for synthetic gibbsite nanoparticles ( $20 \mathrm{~nm}$ thick platelets), while commercial microparticles could be titrated with negligible hysteresis. In our opinion, enhanced dissolution of the nanoscale particles [12] cannot be excluded as one of the rational reasons of the pronounced hysteresis. Titration of such samples cannot characterize surface charge density, and it cannot be applied for thermodynamic calculations. Since reversibility tests reflect all types of irreversible processes (e.g., pore diffusion constraints, capillary effects or surface chemical reactions) in addition to dissolution, independent experiments must be performed to disclose the mechanism behind the hysteresis, with the aim 
of eliminating it, if possible. An example of the vital importance of the nanoparticle solubility is given in the paper of Soenen at al [58]. They demonstrate that the increase in toxicity is directly connected with the increasing metal ion concentration, resulting from cellular dissolution of nanoparticles.

In the above examples, we have discussed the effect of such proton consuming processes that may occur in parallel with surface protonation/deprotonation at the oxide/electrolyte interface. To identify them and eliminate if possible, it is inevitable that the experimental setup itself lacks for any kinds of artefact. The most important procedure of excluding artefacts is the proper conditioning of the $\mathrm{pH}$ electrodes. $\mathrm{pH}$ buffer calibration, i.e., testing the validity of Nernst equation $\left(\mathrm{E}=-2.303(\mathrm{RT} / \Delta \mathrm{zF}) \cdot\left(\mathrm{pH}-\mathrm{pH}_{\mathrm{ref}}\right)\right.$, eq. 6), is routinely used in general, but the great potentiality in checking the linearity of the plots $10^{-\mathrm{pH}}$

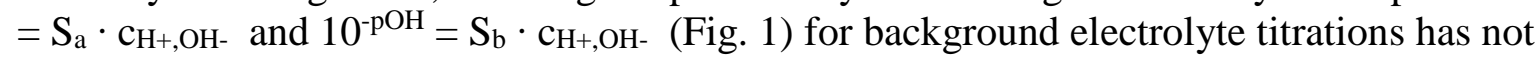
been exploited yet. Although without it, electrode malfunction remains hidden. We present an example of it Fig. 7 for the titrations of the purified titania sample. The titrations were performed independently with two different electrodes, one of which had linear response in the background electrolyte (Fig. 1a) and the other had not (Fig. 2b). Both electrodes gave correct Nernstian response in the $\mathrm{pH}$ buffer calibrations, as detailed in section 4.1. It is clearly seen in Fig. 7 that using the malfunctioned electrode ruins the reversibility of up and down titrations, changes the slopes of the net proton consumption vs. $\mathrm{pH}$ functions, and shifts the $\mathrm{pH}$ of zero net proton consumption. We must note that background electrolyte titrations in our method exclude $a$ priori the non-linearly responding electrodes from the titration of dispersions. Other methods that do not test the electrode in the background electrolytes miss the information about its ideal response or failure; and accordingly, the results can equally be correct or false and there is no way to know, which one occurs actually.

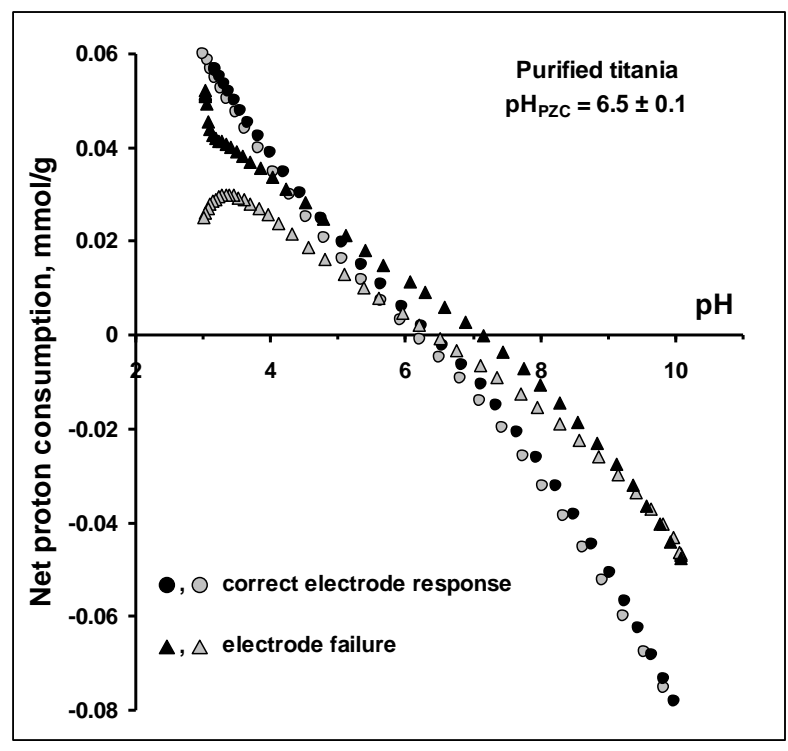

Fig. 7. Comparing reversibility of up (black symbols) and down (grey symbols) titrations of the purified titania sample in $0.05 \mathrm{M} \mathrm{KCl}$ using two different electrodes, the response of which in the background electrolyte is linear (circles) and is non-linear (triangles).

The flow chart in Fig. 8 summarizes the procedure of potentiometric acid-base titrations detailed in the present paper. The sequence of titrations and the necessary tests and actions to eliminate or correct the possible experimental errors and artefacts can be followed easily. The success of our procedure is due to the following novel, non-standard elements embedded in the protocol: 
First of all, the double calibration is essential to check the Nernstian response of the electrode in the actual background electrolytes through the linear functions i) $\mathrm{E}(\mathrm{mV})=\mathrm{f}(\mathrm{pH})$ in buffers and ii) $10^{-\mathrm{pH}}=\mathrm{f}\left(\mathrm{c}_{\mathrm{H}+}\right)$ and $10^{-\mathrm{pOH}}=\mathrm{f}\left(\mathrm{COH}_{-}\right)$in background electrolytes. The blank titrations performed in addition to buffer calibration are exploited in a fully new sense. They are used to test the electrode performance in the background electrolytes. Only the electrodes that respond ideally to proton concentration qualify for use in oxide titrations.

Furthermore, the blank titrations are used as proton concentration calibrations (specific to the actual electrode/electrolyte solution system) to calculate the amount of proton consumption in the corresponding oxide titrations. This allows conversion of the $\mathrm{pH}$ values measured in the oxide dispersions to proton concentrations in an exact way, using only material balance equations.

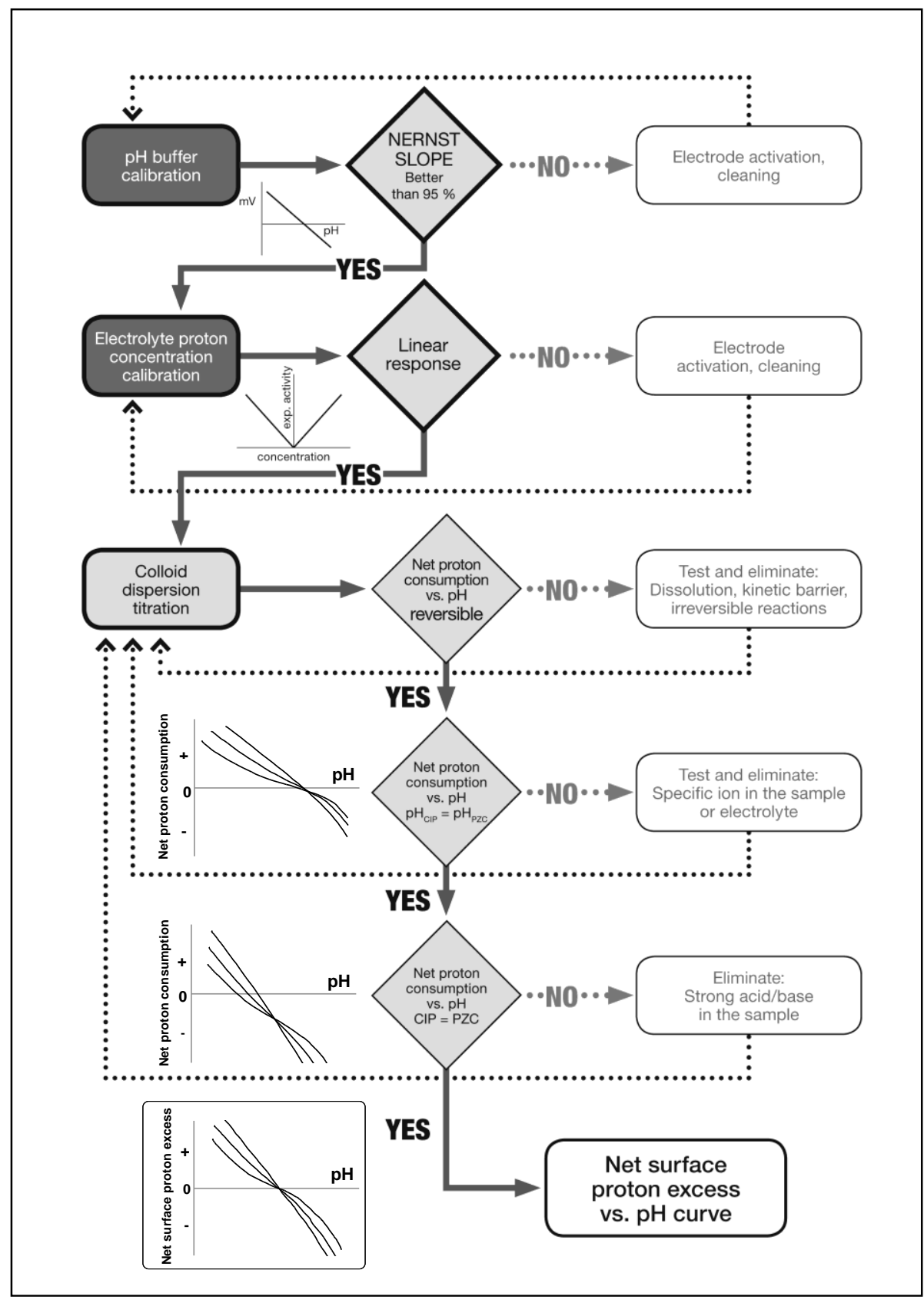

Fig. 8. The flow chart of the procedure of potentiometric acid-base titrations of oxides. 
Next, the result of the oxide titrations is regarded strictly as net proton consumption. The primary net proton consumption vs. $\mathrm{pH}$ functions must fulfil the following criteria in order to consider them as net specific surface proton excess functions: i) reversible up and down curves, ii) appropriate ionic strength dependence and iii) coincidence of cip and PZC. If cip is not PZC, one must search for the presence of specific ions and free acid/base; then adequate purification of the oxide sample must be performed. If $\mathrm{pH}_{\text {cip }}$ depends on the quality of background electrolyte and so $\mathrm{pH}_{\mathrm{cip}} \neq \mathrm{pH} \mathrm{pHZ}_{\mathrm{PZC}}$, the experiment shows the presence of specific adsorption. If $\mathrm{pH}_{\text {cip }}=\mathrm{pH}_{\mathrm{PZC}}$ (i.e., $\mathrm{pH}$ at cip is the same in various background electrolytes and so it can be regarded as $\mathrm{pH}_{\mathrm{PZC}}$ ) and still cip $\neq \mathrm{PZC}$, the experiment shows the presence of some acid or base impurity. After purification, the ideal condition of surface charging experiments can be achieved: cip=PZC. (The difference between $\mathrm{pH}_{\text {cip }}$ and cip and between $\mathrm{pH}$ PZC and PZC is discussed in section 4.2. Surface charge vs. $p H$ functions.)

In the view of the variety of possible reasons of discrepancy between cip and PZC, the simple shift of cip to PZC is not advised. Complying with the protocol ensures intrinsic net specific surface proton excess vs. $\mathrm{pH}$ curves and chemically justifiable, inherent values of PZC of oxides. Otherwise, the notion of net proton consumption is retained, to prevent any confusion with surface charging. Surface charge density vs. pH curves can be calculated from the net specific surface proton excess values, if the reliable specific surface area available for surface charging is known.

\section{Conclusions}

Plenty of contradictory, chemically questionable data of $\mathrm{pH}$-dependent surface charging of amphoteric oxides initiate the demand of a profound re-examination. The recent boom of oxide nanoparticles' usage has definitely confirmed it, especially knowing the enhanced sensitivity of nanosystems to the execution of experiments. We analysed the sources of mistakes in the acid-base titration method systematically. Numerous weaknesses of seemingly well-established practices became evident for us, the discussion of which may contribute to clear up the chemical nonsense of widely scattered PZCs in literature. Our efforts to solve these problems are in line with those of Lützenkirchen and co-workers (see for example in $[22,54,57])$, who have also found that "true" surface charge values cannot be obtained from the titrations mainly because of impurities, data imprecision and side effects. The careful survey of possible errors in titrations presented here is based on our experience of decades' standing; the conclusion is a comprehensive method to assess pure surface protonation/deprotonation equilibria of metal oxides established theoretically and proven in practice. The protocol of titrations discussed in this paper is a straightforward and easily applicable tool that we propose to use widely. It is practically feasible for all researchers interested in preparing and tailoring nanoparticles/nanocomposites, studying environmental fate or toxicity of nanoparticles, in addition to its primary applicability to the problems of colloidal stability and surface complexation modelling.

The double calibration method is a very useful tool to check the correct electrode behaviour (Nernstian response) in the actual background electrolytes, which allows us to evaluate measured data using only material balance equations. The evaluation procedure cannot account for the effect of specifically adsorbing ions; these must be removed experimentally. We should emphasize that specific effect of ions can occur not only at the oxide surface but also at the electrode membrane; these two effects have to be differentiated. In case of oxide dissolution, reversibility can be improved with titrating only within the $\mathrm{pH}$ range of chemical stability. 
In addition to the exact characterization of surface protonation/deprotonation processes, the procedure described here provides high quality proton analytics, extremely useful in many other applications as well. For example, experimental determination of pKs and exact analytical concentrations of monomeric or polymeric weak acids and bases, evaluation of the degree of dissociation of individual amino acids in proteins to provide reliable experimental data for protein charge calculation models, or performing $\mathrm{pH}$-stating via calculating the exact amounts of titrant additions in catalytic [59] or enzyme reactors. In continuation, we plan to present a series of papers about the application of the procedure discussed here to different other colloids, such as polymeric weak acids and bases (e.g., polyacrylic acids, chondroitin sulphate, chitosans), humic acids, clay minerals, mixed oxides, proteins and enzymes.

\section{Acknowledgement}

Financial support of OTKA NK 84014 is acknowledged. We are grateful to Dr. Arie de Keizer for his invaluable contribution in elaboration of the method of linear proton concentration calibration, and for his help in working out our titration software GIMET-1, which closely follows the one, used in the titrations presented in Arie de Keizer's publications. We thank Zsuzsanna Bakó for graphic design of the flow chart.

\section{References}

[1] A. Navrotsky, Energetics of nanoparticle oxides: interplay between surface energy and polymorphism, Geochem. Trans. 4 (2003) 34-37.

[2] M. Delay, F. H. Frimmel, Nanoparticles in aquatic systems, Anal. Bioanal. Chem. 402 (2012) 583-592.

[3] M. Baalousha, A. Manciulea, S. Cumberland, K. Kendall, J. R. Lead, Aggregation and surface properties of iron oxide nanoparticles: Influence of $\mathrm{pH}$ and natural organic matter, Environ. Toxicol. Chem. 27 (2008) 1875-1882.

[4] S. Pakrashi, S. Dalai, D. Sabat, S. Singh, N. Chandrasekaran, A. Mukherjee, Cytotoxicity of $\mathrm{Al}_{2} \mathrm{O}_{3}$ nanoparticles at low exposure levels to a freshwater bacterial isolate, Chem. Res. Toxicol. 24 (2011) 1899-1904.

[5] A. M. Studer, L. K. Limbach, L. Van Duc, F. Krumeich, E. K. Athanassiou, L. C. Gerber, H. Moch, W. J. Stark, Nanoparticle cytotoxicity depends on intracellular solubility: comparison of stabilized copper metal and degradable copper oxide nanoparticles, Toxicol. Lett. 197 (2010) 169-174.

[6] Y.-W. Huang, C.-h. Wu, R. S. Aronstam, Toxicity of transition metal oxide nanoparticles: recent insights from in vitro studies, Materials 3 (2010) 4842-4859.

[7] Ö. Sahin, A. N. Bulutcu, Effect of surface charge distribution on the crystal growth of sodiumperborate tetrahydrate, J. Crystal Growth 241 (2002) 471-480.

[8] G. A. Parks, P. L. de Bruyn, The zero point of charge of oxides, J. Phys. Chem. 66 (1962) 967-973.

[9] R. O. James, G. A. Parks, Characterization of aqueous colloids by their electrical doublelayer and intrinsic surface chemical properties, in: E. Matijevic (Ed), Surface and Colloid Science, vol. 12, Plenum Press, New York, 1982, pp. 119-216.

[10] W. Stumm, Chemistry of the Solid-Water Interface, Wiley, New York, 1992.

[11] Lyklema, J. Fundamentals of Interface and Colloid Science, Solid-Liquid Interfaces, Vol. II., Academic Press, London, 1995.

[12] E. Tombácz, Adsorption from electrolyte solutions, in: J. Tóth (Ed.), Adsorption: Theory, Modeling and Analysis, Marcel Dekker, New York, 2002, pp. 711-742. 
[13] G. A. Parks, The isoelectric points of solid oxides, solid hydroxides, and aqueous hydroxo complex systems, Chem. Rev. 65 (1965) 177-198.

[14] M. Kosmulski, The significance of the difference in the point of zero charge between rutile and anatase, Adv. Colloid Interface Sci. 99 (2002) 255-264.

[15] M. Kosmulski, The $\mathrm{pH}$-dependent surface charging and points of zero charge: V. update, J. Colloid Interface Sci. 353 (2011) 1-15.

[16] M. Kosmulski, Chemical properties of material surfaces, in: M. J. Schick and A. T. Hubbard (Eds.), Surfactant Science Series, 102, Marcel-Dekker, New York, 2001.

[17] R. P. Buck, S. Rondinini, A. K. Covington, G. K. Baucke, C. M. A. Brett, M. F. Camoes, M. J. T. Milton, T. Mussini, R. Naumann, K. W. Pratt, P. Spitzer, G. S. Wilson, Measurement of $\mathrm{pH}$. Definition, standards, and procedures, Pure Appl. Chem. 74 (2002) 2169-2200. (IUPAC Recommendations)

[18] R. G. Bates, Determination of pH, Wiley, New York, 1973.

[19] M. F. Camões, Century of pH measurement, Chemistry International 32 (2010) 3-7.

[20] T. Preoĉanin, N. Kallay, Application of "mass titration" to determination of surface charge of metal oxides, Croat. Chem. Acta 71 (1998) 1117-1125.

[21] P. M. Dove, C. M. Craven, Surface charge density on silica in alkali and alkaline earth chloride electrolyte solutions, Geochim. Cosmochim. Ac. 69 (2005) 4963-4970.

[22] J. Lützenkirchen, J.F. Boily, L. Gunneriusson, L. Lövgren, S. Sjöberg, Protonation of different goethite surfaces-Unified models for $\mathrm{NaNO}_{3}$ and $\mathrm{NaCl}$ media, J. Colloid Interface Sci. 317 (2008) 155-165.

[23] C. J. Milne, D. G. Kinniburgh, J. C. M. De Wit, W. H. Van Riemsdijk, L. K. Koopal, Analysis of proton binding by a peat humic acid using a simple electrostatic model, Geochim. Cosmochim. Ac. 59 (1995) 1101-1112.

[24] G. Sposito, Characterization of particle surface charge, in: J. Buffle, H. P. van Leeuwen, IUPAC, Environmental Particles, Volume 1, Environmental Analytical and Physical Series, Lewis Publishers Inc., Michigan, 1992, pp. 291-314.

[25] C. Tanford, The interpretation of hydrogen ion titration curves of proteins, Adv. Protein Chem. 17 (1963) 69-165.

[26] D. Cakara, M. Kobayashi, M. Skarba, M. Borkovec, Protonation of silica particles in the presence of a strong cationic polyelectrolyte, Colloids Surfaces A 339 (2009) 20-25.

[27] D. J. Winzor, Determination of the net charge (valence) of a protein: a fundamental but elusive parameter, Anal. Biochem. 325 (2004) 1-20.

[28] A. R. Günther, M.M. Santoro and E. Rogana, $\mathrm{pH}$ titration of native and unfolded Btrypsin: evaluation of the $\Delta \Delta \mathrm{G}^{0}$ titration and the carboxyl pK values, Braz. J. Med. Biol. Res. 30 (1997) 1281-1286.

[29] M. Kosmulski, Chemical properties of material surfaces, in: A. T. Hubbard (Ed.), Surfactant Science Series, vol. 102, Marcel Dekker, New York - Basel, 2001, p. 65.

[30] M. K. Ridley, M. L. Machesky, D. A. Palmer, D. J. Wesolowski, Potentiometric studies of the rutile-water interface: hydrogen-electrode concentration-cell versus glass-electrode titrations, Colloids Surfaces A 204 (2002) 295-308.

[31] A. A. Keller, H. Wang, D. Zhou, H. S. Lenihan, G. Cherr, B. J. Cardinale, R. Miller, Z. Ji, Stability and aggregation of metal oxide nanoparticles in natural aqueous matrices, Environ. Sci. Technol. 44 (2010) 1962-1967.

[32] W.-S. Cho, R. Duffin, F. Thielbeer, M. Bradley, I. L. Megson, W. MacNee, C. A. Poland, C. L. Tran, K. Donaldson, Zeta potential and solubility to toxic ions as mechanisms of lung inflammation caused by metal/metal oxide nanoparticles, Toxicol. Sci. 126 (2012) 469477. 
[33] S. Dufort, L. Sancey, J.-L. Coll, Physico-chemical parameters that govern nanoparticles fate also dictate rules for their molecular evolution, Adv. Drug Delivery Rev. 64 (2012) 179189.

[34] P. Atkins, J. de Paula, Atkins' Physical Chemistry, Seventh Edition, Oxford University Press, 2002, p. 268.

[35] N. Kallay, T. Preočanin, T. Ivšić, Determination of surface potentials from the electrode potentials of a single-crystal electrode, J. Colloid Interface Sci. 309 (2007) 21-27.

[36] J. Lyklema, Nomenclature, symbols, definitions and measurements for electrified interfaces in aqueous dispersions of solids (Recommendations 1991), Pure Appl. Chem. 63 (1991) 895-906.

[37] D. H. Everett, Reporting data on adsorption from solution at the solid/solution interface (Recommendations 1986), Pure Appl. Chem. 58 (1986) 967-984.

[38] Application Bulletin 271/4 e, Validation of Metrohm pH meters using Standard Operating Procedures http://products.metrohm.com/getAttachment.axd?attaName=e7af30ce3e18-465e-ba0c-af5cc96324b7

[39] S. F. Oman, M. F. Camões, K. J. Powell, R. Rajagopalan, P. Spitzer, Guidelines for potentiometric measurements in suspensions Part A. The suspension effect, Pure Appl. Chem. 79 (2007) 67-79.

[40] S. F. Oman, M. F. Camões, K. J. Powell, R. Rajagopalan, P. Spitzer, Guidelines for potentiometric measurements in suspensions Part B. Practical pH measurements in soil suspensions, Pure Appl. Chem. 79 (2007) 81-68.

[41] G. Gran, Determination of the equivalent point in potentiometric titrations, Acta Chem. Scand. 4 (1950) 559-557.

[42] E. Tombácz, M. Szekeres, Interfacial acid-base reactions of aluminum oxide dispersed in aqueous electrolyte solutions. 1. Potentiometric study on the effect of impurity and dissolution of solid phase, Langmuir 17 (2001) 1411-1419.

[43] E. Illés, E. Tombácz, The role of variable surface charge and surface complexation in the adsorption of humic acid on magnetite, Colloids Surfaces A 230 (2003) 99-109.

[44] E. Tombácz, Z. Libor, E. Illés, A. Majzik, E. Klumpp, The role of reactive surface sites and complexation by humic acids in the interaction of clay mineral and iron oxide particles, Org. Geochem. 35 (2004) 257-267.

[45] E. Tombácz, M. Szekeres, Colloidal behavior of aqueous montmorillonite suspensions: the specific role of $\mathrm{pH}$ in the presence of indifferent electrolytes, Appl. Clay Sci. 27 (2004) 75-94.

[46] M. Szekeres, J. Tóth, I. Dékány, Specific surface area of stoeber silica determined by various experimental methods, Langmuir 18 (2002) 2678-2685.

[47] E. Tombácz, M. Szekeres, Effects of impurity and solid-phase dissolution on surface charge titration of aluminium oxide, Prog. Colloid Polym. Sci. 117 (2002) 18-26.

[48] A. W. P. Vermeer, L. K. Koopal, Charge Adjustments upon adsorption of a weak polyelectrolyte to a mineral oxide: the hematite-humic acid system, J. Colloid Interface Sci. 212 (1999) 176-185.

[49] W. F. Tan, L. K. Koopal, L. P. Weng, W. H. van Riemsdijk, W. Norde, Humic acid protein complexation, Geochim. Cosmochim. Ac. 72 (2008) 2090-2099.

[50] J. Lyklema, Points of zero charge in the presence of specific adsorption, J. Colloid Interface Sci. 99 (1984) 109-117.

[51] W. Rudzinski, W. Piasecki, G. Panas, R. Charmas, Calorimetric effects and temperature dependence of simple ion adsorption at oxide/electrolyte interfaces: the systems in which PZC and CIP do not coincide, J. Colloid Interface Sci. 226 (2000) 353-363. 
[52] S. Mustafa, B. Dilara, Z. Neelofer, A. Naeem, S. Tasleem, Temperature effect on the surface charge properties of $\gamma-\mathrm{Al}_{2} \mathrm{O}_{3}$, J. Colloid Interface Sci. 204 (1998) 284-293.

[53] C. Contescu, J. Jagiello, J. A. Schwarz, Heterogeneity of proton binding sites at the oxide/solution interface, Langmuir 9 (1993) 1754-1765.

[54] J. Lützenkirchen, On derivatives of surface charge curves of minerals, J. Colloid Interface Sci. 290 (2005) 489-497.

[55] M. Borkovec, B. Jönsson, G. J. M. Koper, Ionization processes and proton binding in polyprotic processes: small molecules, proteins, interfaces, and polyelectrolytes, in: E.

Matijevic (ed.), Surface and Colloid Science, vol. 16. Kluwer Academic / Plenum Press, 2001, pp. 99-339.

[56] E. Tombácz, pH-dependent surface charging of metal oxides, Period. Polytech. Chem. 53 (2009) 77-86.

[57] F. Adekola, M. Fédoroff, H. Geckeis, T. Kupcik, G. Lefèvre, J. Lützenkirchen, M. Plaschke, T. Preocanin, T. Rabung, D. Schild, Characterization of acid-base properties of two gibbsite samples in the context of literature results, J. Colloid Interface Sci. 354 (2011) 306317.

[58] S.J. Soenen, N. Nuytten, U. Himmelreich, M. De Cuyper, Intracellular iron oxide nanoparticle coating stability determines nanoparticle usability and cell functionality, Drug Discovery Today 15 (2010) 1082.

[59] R. Kun, M. Szekeres, I. Dékány, Photooxidation of dichloroacetic acid controlled by pH-stat technique using TiO2/layer silicate nanocomposites, Appl. Catal. B 68 (2006) 49-58. 